\title{
USING THE ULTRASONIC TOMOGRAPHY METHOD TO STUDY THE CONDITION OF WOODEN BEAMS FROM HISTORICAL BUILDINGS
}

\author{
M. ZIELIŃSKA ${ }^{1 *}$, M. RUCKA ${ }^{2}$ \\ ${ }^{1}$ Department of Technical Fundamentals of Architectural Design, Faculty of Architecture \\ Gdansk University of Technology \\ Narutowicza 11/12, 80-233 Gdansk, Poland \\ e-mail: monika.zielinska@pg.edu.pl (*corresponding author) \\ ${ }^{2}$ Department Mechanics of Materials and Structures, Faculty of Civil Environmental Engineering \\ Gdansk University of Technology \\ Narutowicza 11/12, 80-233 Gdansk, Poland \\ e-mail: magdalena.rucka@pg.edu.pl
}

Keywords: Historical Structure, Wood, Monitoring, Non-Destructive Inspection

\begin{abstract}
The need to evaluate the integrity of wooden structural elements is constantly increasing. Non-destructive methods are becoming more popular in this field of research. One type of non-destructive testing is the ultrasonic imaging method, which allows the analysis of internal wood structures without disturbing their state and integrity. In this study, we are interested in assessing the effect of wood condition on the ultrasound time of flight (TOF). The research was carried out on wooden beams, which were obtained from a historical building. The images obtained from ultrasound tomography were compared with results of a visual inspection.Places of discontinuities, voids and cracks in wood caused a much lower velocity of wave propagation. The location of the wood core was illustrated by the places with the highest velocity. The article proved the validity of using ultrasonic tomography to assess the technical condition of historic wooden beams.
\end{abstract}

\section{INTRODUCTION}

In historical objects, it is essential to preserve as many elements in the original character as possible. It is particularly difficult in the case of wood, which is one of the most susceptible construction materials. Over the years, the wooden structure elements undergo destructive processes. Their development and progress depend on various factors amongst which an important role is played by the historical events that took place while the structure existed. Mechanical wear and long-term mechanical stress together with its consequences are the elements resulting in the destruction of wooden elements of the cultural heritage. Wood is subject to degradation also under the influence of stresses from the humidity changes and insect effect. The fungi decay emerging when the humidity is above $20 \%$, is an important issue in case of wooden objects in civil engineering [1].

Examining the condition of wooden elements is crucial from the perspective of the correct structure performance. Detecting the internal wood condition deterioration without any 
symptoms visible from the outside allows preventing the further spread of the decay. Research conclusions frequently result in the necessity to conduct repairs, renovations, replacement of the wooden beams structure, or even the substitution of a significant part of the structure. Apart from simple tests, such as a visual inspection or tapping to determine the near-surface defects, non-destructive testing (NDT) play an important role in the process. The non-destructive testing on wooden elements are conducted with ground penetrating radar (GPR) [2, 3], thermal techniques [4], microwaves [5], acoustic emission [6], ultrasonic tomography [7] and X-ray tomography [8-11].The use of the ground penetrating radar may be problematic in case of elements of small size. This is when the acoustic test methods are more advantageous, as they allow identifying the heterogeneous or damaged areas based on the time-of-flight value. A map presenting the distribution of a specific parameter, for example, the wave propagation velocity, is created on the basis of the aforesaid values, which facilitates the interpretation of the information on the examined area.

The evaluation of the ultrasonic tomography implementation in wooden elements was first described by Tomikawa et al. [12] in 1986. The measurements taken on the wooden columns provided satisfactory effects; nevertheless, the image was of poor resolution. From that time onwards, the implementation of the ultrasonic tomography for wooden elements is in constant development. Comino et al. [13], Deflorio et al. [14], Brazee et al. [15] used the ultrasonic tomography to evaluate the condition of alive trees. Yan et al. [16] detect discontinuities of non-metallic elements by applying the proposed algorithm on a wooden element. The internal discontinuities were also detected by Alves et al. [177. Colla [18] described the ultrasonic tomography results compared the results destructive methods (unprocessed wood), to detect knots in wh
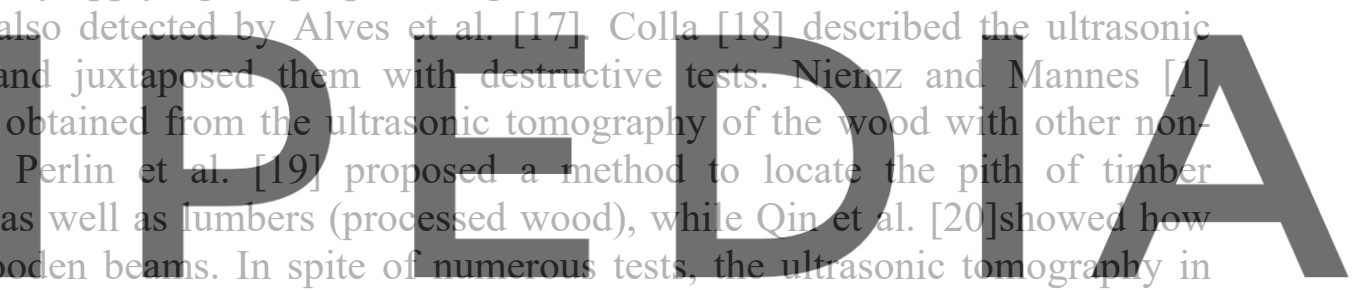

wooden elements can still be a difficult task. The reason for that lies in wood anisotropy,

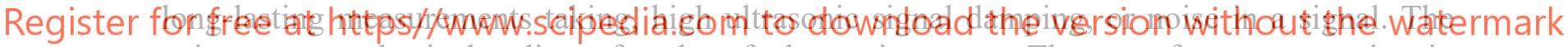
anisotropy results in bending of paths of ultrasonic waves. The wavefront propagating in wood has a deformed shape in comparison to spherical waves obtained for isotropic media. The traditional tomographic imaging takes into account the straight radius transfer. In this particular case, however, the actual waveform shall be taken into account, which is taken up by Espinosa et al. [21, 22].

The paper evaluates the possibility to implement the ultrasonic tomography for wooden beams. Both healthy and defective wood was taken for the purpose of the experimental test. The beams were acquired from the historical object and their degradation was significant. Additionally, in order to compare the results, the measurements were taken also for a new beam with the cross-section corresponding to the historic beams. The paper is focused on the influence of anisotropy condition on the wood ultrasonic wave propagation, by estimating the transfer time. The transfer time measurements were obtained for various transmission and reception points configuration. Their influence on the tomographic image reconstruction was described. 


\section{THEORY OF ULTRASONIC TOMOGRAPHY}

Ultrasound tomography allows determining the internal structure of an element in the examined cross-section (Figure 1). At first, the object should be divided into finite area elements. These elements are called pixels. The resolution of the final image depends on the number of pixels. Then, the information from the ultrasonic signals passing through the element is collected. This information is usually the time of flight (TOF), which can be described by the equation:

$$
\begin{gathered}
t_{i}=\sum_{j=1}^{n} w_{i j} s_{j}, i=1,2,3, \ldots, m, j=1,2,3, \ldots, n, \\
s_{j}=\frac{1}{v_{j}},
\end{gathered}
$$

where $t_{i}$ is the total time from the transmitter to the receiver for $i$-th path, $s j$ is the ultrasonic pulse slowness in pixel $j, v_{j}$ is the ultrasonic pulse velocity in pixel $j, w_{i j}$ is the length of the $i$-th path passing through the $j$-th pixel.
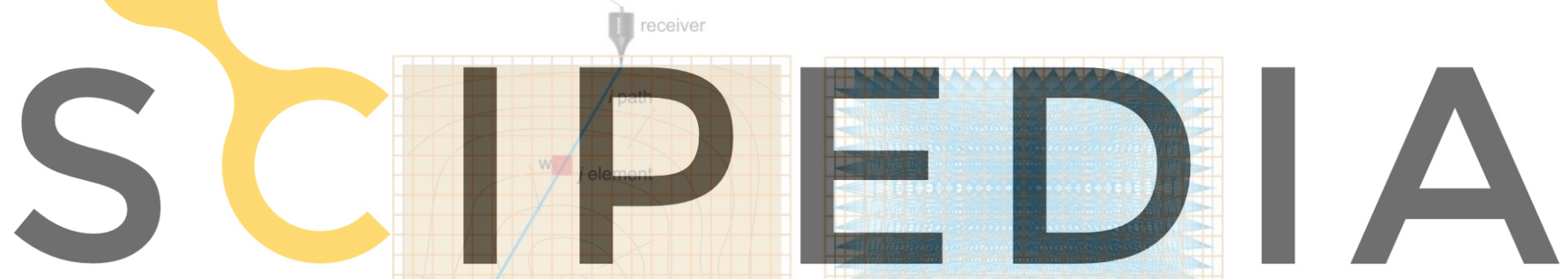

Register for free at https//www.scipedia.com to download the version without the watermark

Figure 1: Scheme of passing: (a) $i$ path through $j$ element, (b) several paths through the object.

Based on known cross-sectional geometry, it is possible to determine the ultrasonic pulse velocity in each pixel. In ultrasound tomography, equation (1) is usually overdetermined or underdetermined. Therefore, usual methods of resolution such as simple inversion or Gaussian elimination cannot be used. The equation can be solved by iterative methods. The calculations presented in this paper are based on the algebraic reconstruction technique (ART) [23], which is described by the following equation:

$$
s_{j}^{(k)}=s_{j}^{(k-1)}+\frac{w_{i j} \Delta t_{i}}{\sum_{j=1}^{n} w_{i j}^{2}},
$$

where $\Delta t_{i}$ is the difference between the measured and the reconstructed time of flight, and the $k$ index symbolizes the step of the iteration. 


\section{MATERIALS AND METHODS}

\subsection{Description of specimens}

The tests were conducted on wooden beams taken from the historical Monastery of Congregation of the Sisters of St. Catherine located in Orneta, in the northern part of Poland (Figure 2). The beams were the elements of a roof framework, which due to its poor technical condition underwent the restoration works.
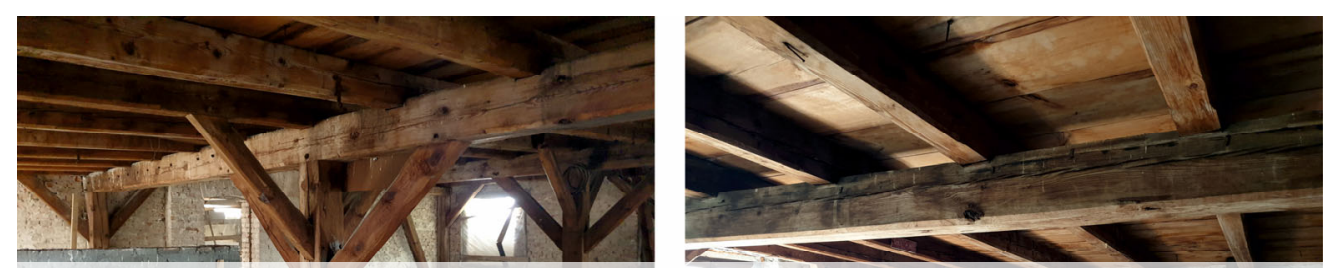

(a)

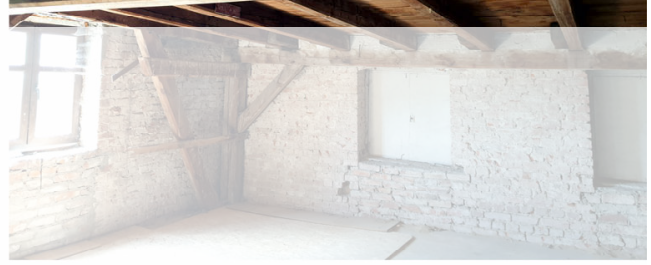

(b)

Figure 2: Photographs of the roof framework from the Monastery of Congregation of the Sisters of St. Catherine
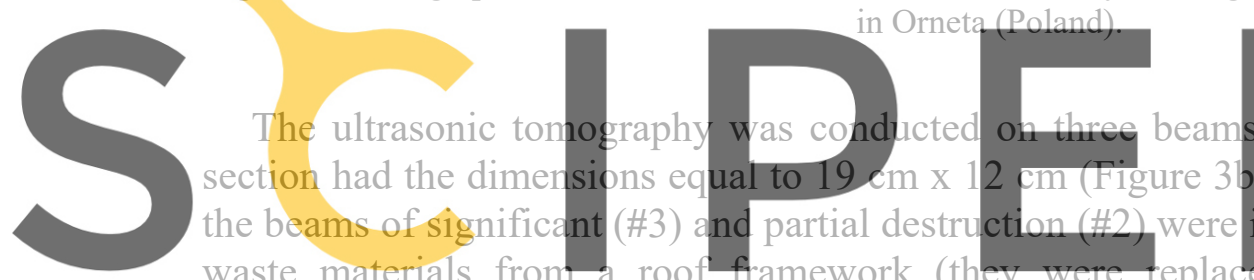

in Orneta (Poland).

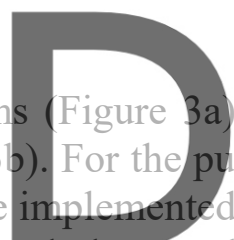

waste materials fron a

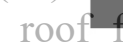

ramework

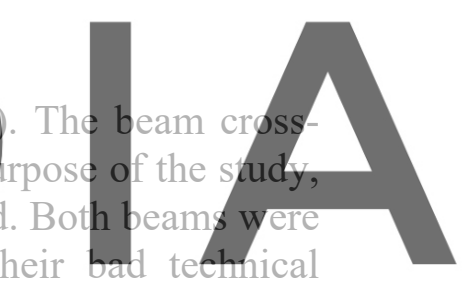

condition by the new wooden beams). The measurements were also taken for a new beam

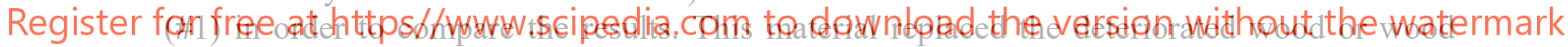
damaged by the insects.

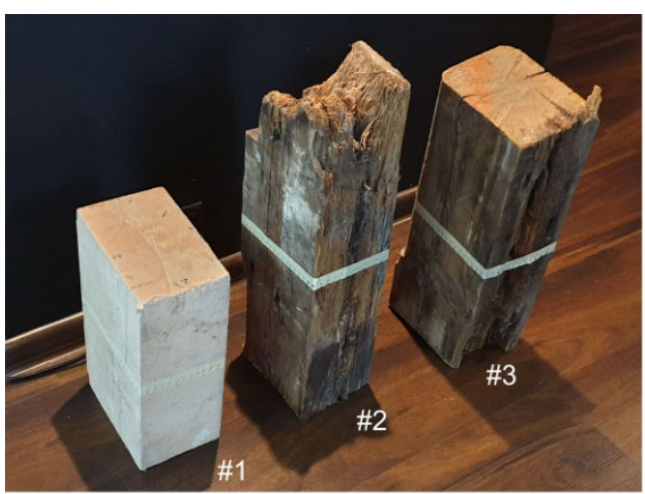

(a)

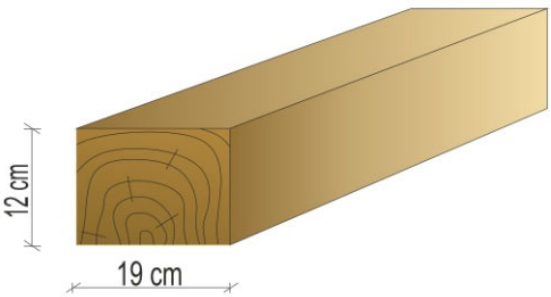

(b)

Figure 3: Laboratory models of wooden beams. 


\subsection{Experimental setup}

Ultrasonic tomography was performed based on measured times of flight for waves passing through the element. Wave signals were measured by the PUNDIT PL-200 instrument (Proceq SA, Schwerzenbach, Switzerland). Two exponential transducers of $54 \mathrm{kHz}$ were used in the through transmission mode. The experimental setup and scheme of image reconstruction are shown in Figure 4.

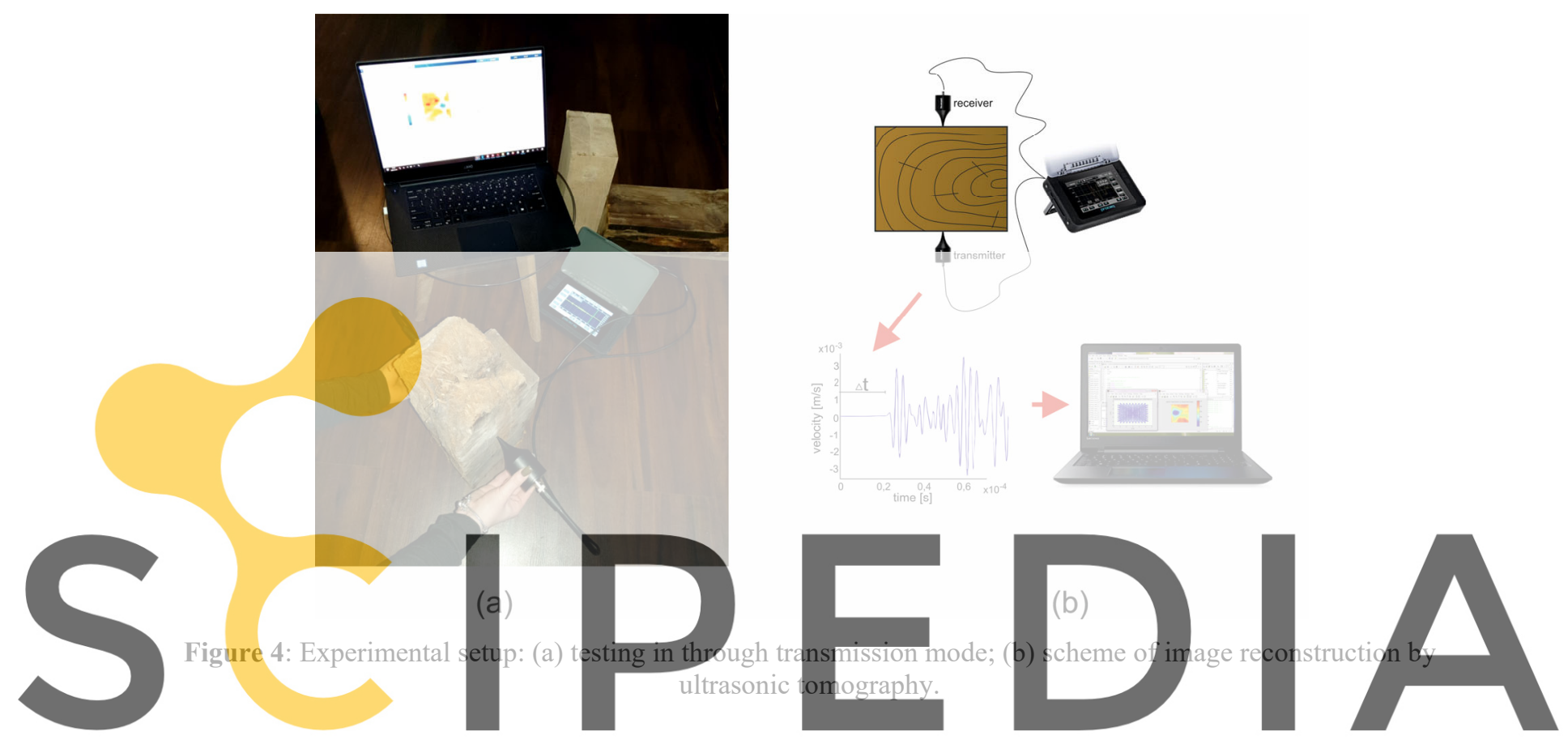

Measurements were carried out in the cross-section located in the middle height of each

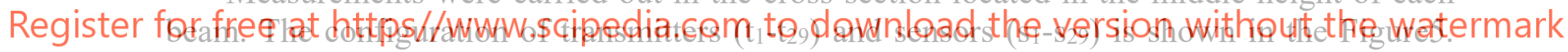

The transmitters and receivers were placed to the edge, with an interval of $1 \mathrm{~cm}$ between each other. The signal for each transmitter was recorded at the receiver points lying on the opposite wall. For each of the beams 445 measurement signals were obtained.

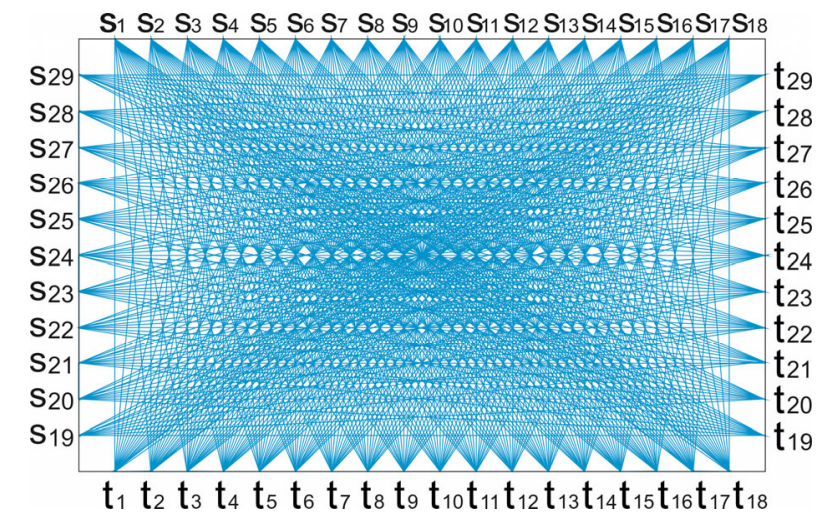

Figure 5: Configuration of the wave paths from transmitters ( $t$ ) to sensors (s). 


\section{RESULTS AND DISCUSSION}

The first laboratory model (\#1) was a new beam. This material was used to replace the wood damaged by insects. The edges were straight and the beam did not have any significant damages or cracks. The internal structure was recreated based on the collected transfer time signals (Figure 6a). A significantly higher velocity was observed in the upper part of the map. This place indicates the location of the cross section's core. The signals collected from the transmitters $t_{1}-t_{18}$ showed major differences between the waveforms' velocities. They ranged from 650 to $1550 \mathrm{~m} / \mathrm{s}$. For each of the transmitters $\mathrm{t}_{1}-\mathrm{t}_{18}$ a waveform with the highest wave propagation velocity was chosen. The waveforms were marked in red in Figure 6b. It was observed that the intersection of the waveforms indicates the exact location of the wooden element's core. (Figure 6c). The wave propagation velocities from the transmitters $t_{19}$ $-\mathrm{t}_{29}$ did not indicate equally high differences between each other $(900-1150 \mathrm{~m} / \mathrm{s})$.

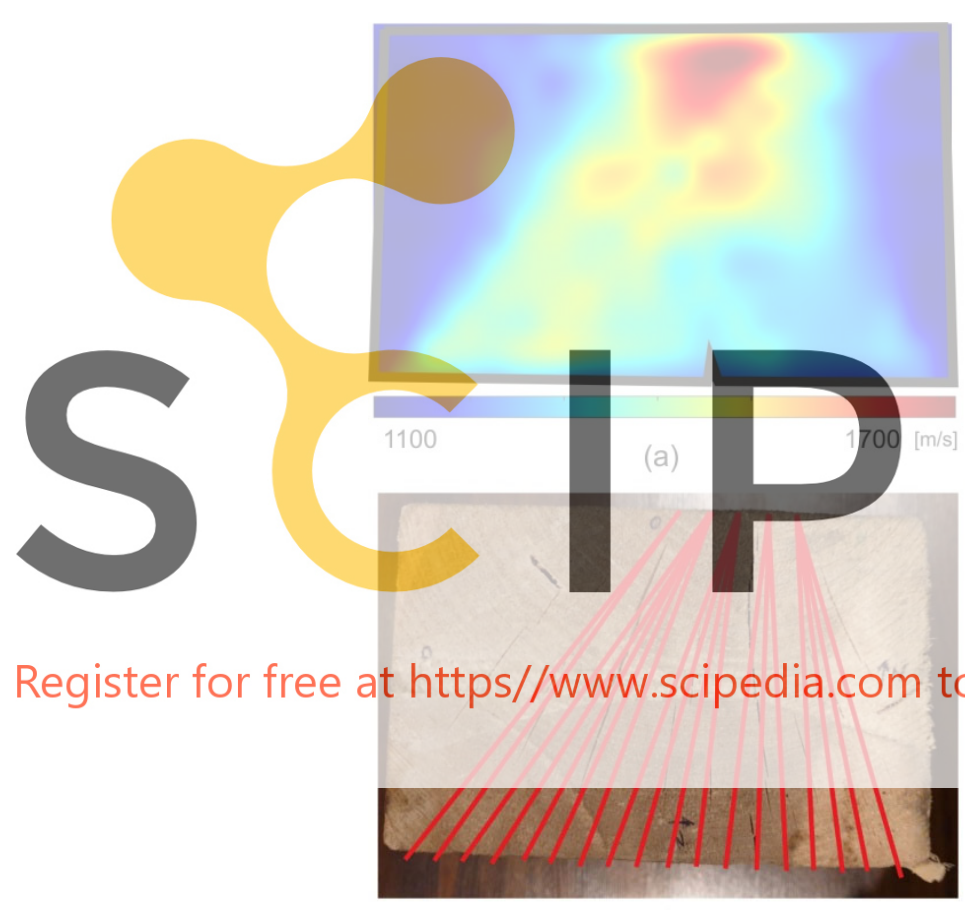

(c)

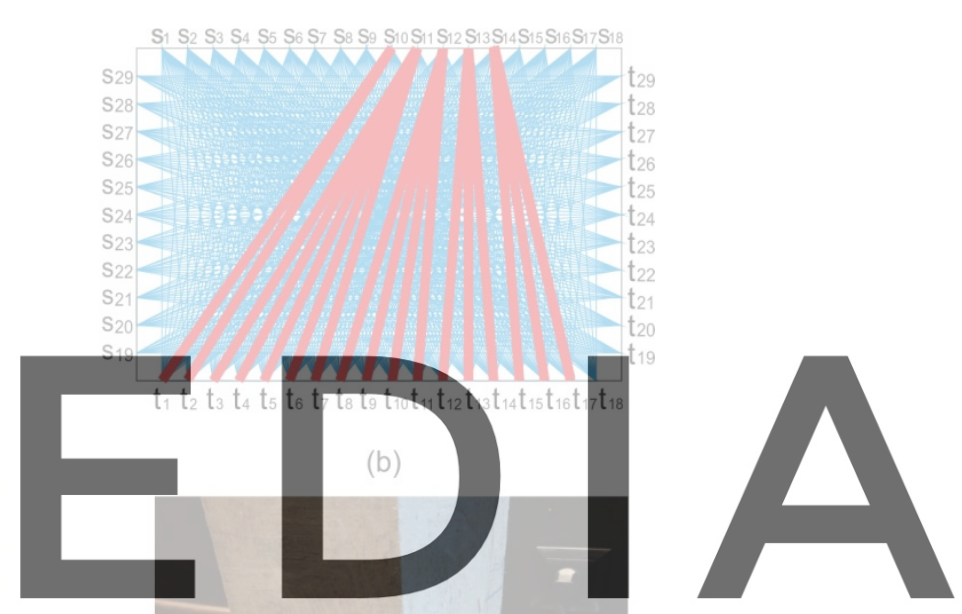

download the version without the watermark

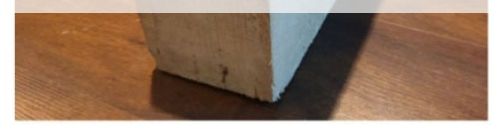

(d)

Figure 6: Results obtained for beam \#1: (a) ultrasound tomography image, (b) ray paths with the fastest paths marked for $\mathrm{t}_{1}-\mathrm{t}_{18}$ transmitters, (c) top view of the beam, (d) side view of the beam.

Beam \#2 was taken from the historical roof framework. One of its sides included a major wood fibrosis (Figure 7c). The remaining three contained cracks. The ultrasonic tomography image clearly shows the places where the beam is damaged (Figure 7a). The edge with the wood fibrosis showed the reduced wave transfer velocity. A similar effect was observed in places where the cracks were located. Furthermore, an increased velocity may be spotted at the location of the cross-sections core, similarly to the reference beam (\#1). 

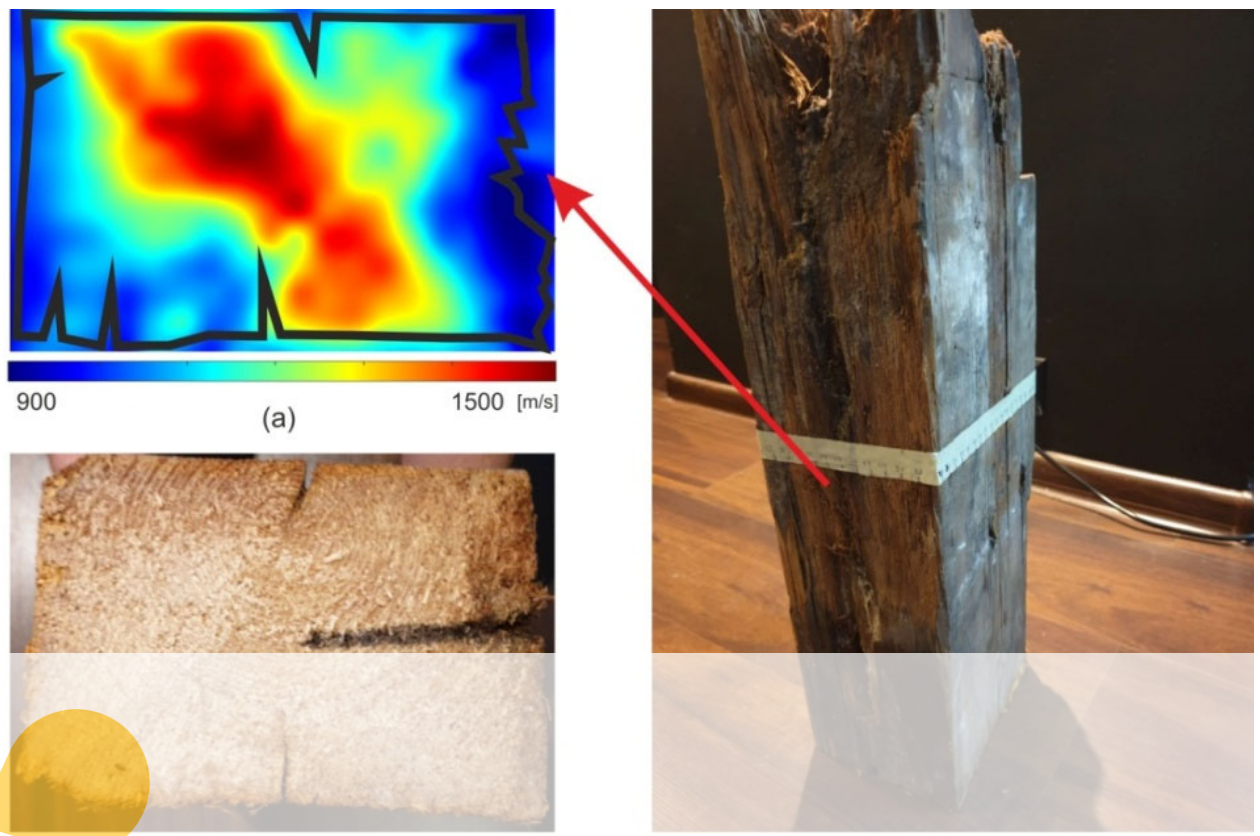

(c)

(b)

Figure 7: Results obtained for beam \#2: (a) ultrasound tomography image, (b) top view of the beam, (c) side
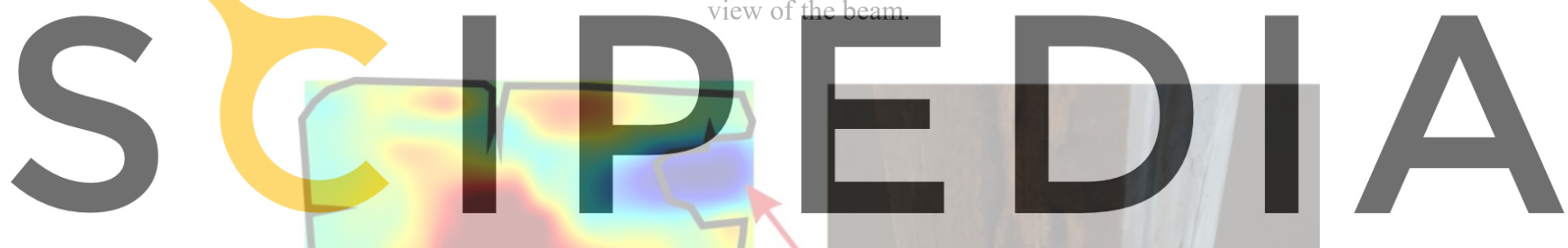

Register for free at https//www.scipedia.com to download the version without the watermark

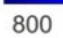

(a)

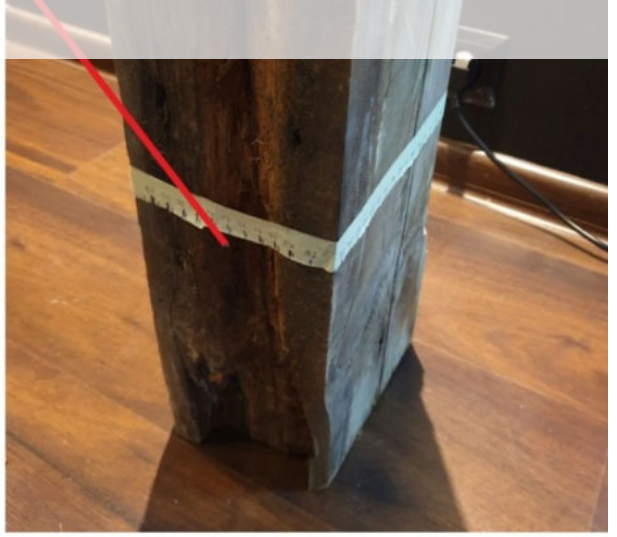

(b)

(c)

Figure 8: Results obtained for beam \#3: (a) ultrasound tomography image, (b) top view of the beam, (c) side view of the beam. 
The beam \#3 had the highest level of degradation. One of the sides included a significant cavity caused by insects (Figure 8c). This place is marked in blue on the ultrasonic tomography map (Figure 8a). The remaining sides included cracks. The biggest crack was marked on the tomographic image. Similarly to beam \#1 and \#2 the greatest concentration of the wave propagation velocity determined the location of the wood cross section's core.

\section{CONCLUSIONS}

The article describes experimental research conducted on wooden beams from a historical object. Two damaged beams were used for the research, and their technical condition was determined employing the ultrasonic tomography. The obtained results were compared with the tomography performed for a new, undamaged beam with equal cross-section dimensions.

The conducted research aimed at evaluating the possibility to use the ultrasonic waves for imaging the internal structure of historical wood. It was focused on the reconstruction of tomographic velocity in chosen cross-sections that enabled the development of the method allowing to identify the location of the wood cross-section core. For the correct interpretation of the obtained tomographic image, it is essential. The areas with wood fibrosis and damages caused by insect activity indicate the significant reduction in the tomographic velocity. A similar effect is visible in places where the cracks in wood occur.

The ultrasonic tomography is an effective tool enabling the reconstruction of the internal cross-section of the examined wooden element. The presented approach may be used to evaluate the quality of the wooden beams, which damages are not always in plain sight. Owing to this, a mord effective plan of vooden structure repair prepared and used for historical objects. Furt without the necessity
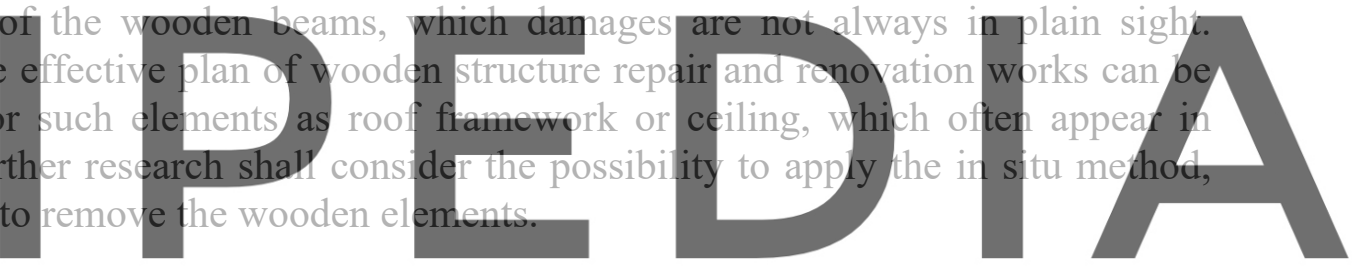

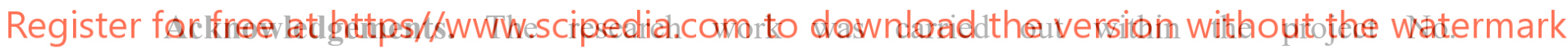
2017/27/N/ST8/02399, financed by the National Science Centre, Poland.

\section{REFERENCES}

[1] P. Niemz and D. Mannes, "Non-destructive testing of wood and wood-based materials," J. Cult. Herit., vol. 13, no. 3, pp. S26-S34, 2012.

[2] T. C. Mai, S. Razafindratsima, Z. M. Sbartaï, F. Demontoux, and F. Bos, "Nondestructive evaluation of moisture content of wood material at GPR frequency," Constr. Build. Mater., vol. 77, pp. 213-217, 2015.

[3] R. Martínez-Sala, I. Rodríguez-Abad, R. Diez Barra, and R. Capuz-Lladró, "Assessment of the dielectric anisotropy in timber using the nondestructive GPR technique," Constr. Build. Mater., vol. 38, pp. 903-911, 2013.

[4] V. Bucur, "Techniques for high resolution imaging of wood structure: A review," Meas. Sci. Technol., vol. 14, no. 12, 2003.

[5] M. Pastorino et al., "A microwave tomographic system for wood characterization in the forest products industry," Wood Mater. Sci. Eng., vol. 10, no. 1, pp. 75-85, 2015. 
[6] F. C. Beall, "Overview of the use of ultrasonic technologies in research on wood properties," Wood Sci. Technol., vol. 36, no. 3, pp. 197-212, 2002.

[7] A. Arciniegas, F. Prieto, L. Brancheriau, and P. Lasaygues, "Literature review of acoustic and ultrasonic tomography in standing trees," Trees - Struct. Funct., vol. 28, no. 6 , pp. 1559-1567, 2014.

[8] P. Nilakantan, "X-ray studies of wood, lignin and wood-cellulose," Proc. Indian Acad. Sci. - Sect. A, vol. 5, no. 2, pp. 166-174, 1937.

[9] Q. Wei, B. Leblon, and A. la Rocque, "On the use of X-ray computed tomography for determining wood properties: A review 1," Can. J. For. Res., vol. 41, no. 11, pp. 2120 2140, 2011.

[10] K. Kobayashi, S. W. Hwang, T. Okochi, W. H. Lee, and J. Sugiyama, "Non-destructive method for wood identification using conventional X-ray computed tomography data," J. Cult. Herit., vol. 38, pp. 88-93, 2019.

[11] J. L. Paris and F. A. Kamke, "Quantitative wood-adhesive penetration with X-ray computed tomography," Int. J. Adhes. Adhes., vol. 61, pp. 71-80, 2015.

[12] Y. Tomikawa, "Non destructive Inspection of wooden Poles using Ultrasonic Tomogrphy," IEEE Trans. UFFC, vol. 33, pp. 354-358, 1986.

[13] E. Comino, V. Socco, R. Martinis, G. Nicolotti, and L. Sambuelli, "Ultrasonic tomography for wood decay diagnosis.," in International Symposium on Plant Health in Urban Horticulture, Braunschweig, 2000, p. 279.

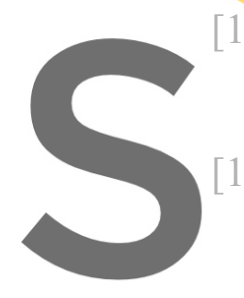

[14] G. Deflorio, S. G. Deflorio, S. Fink, and F. W. M. R. Schwarze, "Det
stems with sonic tomography atter wounding and
Technol., vol. 42, no. 2, pp. 117-132, 2008 .
N. J. Brazee, R. E. Marra, L. Göcke, and I. Van
assessment of internal decay in three hardwood specie
using sonic and electrical impedance tomogranhy." Fo 2011.

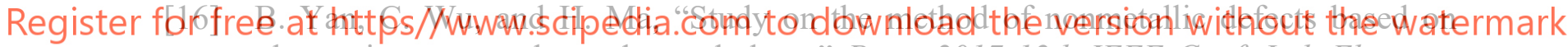
ultrasonic tomography and morphology," Proc. 2017 12th IEEE Conf. Ind. Electron. Appl. ICIEA 2017, vol. 2018-Febru, pp. 1287-1292, 2018.

[17] R. C. Alves, J. N. R. Mantilla, C. F. Bremer, and E. V. M. Carrasco, “Application of Acoustic Tomography and Ultrasonic Waves to Estimate Stiffness Constants of Muiracatiara Brazilian Wood," vol. 10, no. 2010, pp. 1845-1856, 2015.

[18] C. Colla, "Verification of sonic tomography outcome through local testing of mechanical properties in historic timber beam," J. Herit. Conserv., vol. 47, pp. 71-79, 2016.

[19] L. P. Perlin, Â. Valle, R. Caldas, and D. A. Pinto, "New method to locate the pith position in a wood cross-section based on ultrasonic measurements," vol. 169, pp. 733739, 2018.

[20] J. Qin, X. Liu, K. Van Den Abeele, and G. Cui, "The study of wood knots using acoustic nondestructive testing methods," Ultrasonics, vol. 88, pp. 43-50, 2018.

[21] L. Espinosa, F. Prieto, L. Brancheriau, and P. Lasaygues, "Effect of wood anisotropy in ultrasonic wave propagation: A ray-tracing approach," vol. 91, no. April 2018, pp. 242-251, 2019.

[22] L. Espinosa, F. Prieto, L. Brancheriau, and P. Lasaygues, "Quantitative parametric 
imaging by ultrasound computed tomography of trees under anisotropic conditions : Numerical case study," Ultrasonics, no. 26, p. 106060, 2019.

[23] A. C. Kak and M. Slaney, Principles of Computerized Tomographic Imaging. New York: The Institiute of Electrical and Electronics Engineers, Inc., 1988.
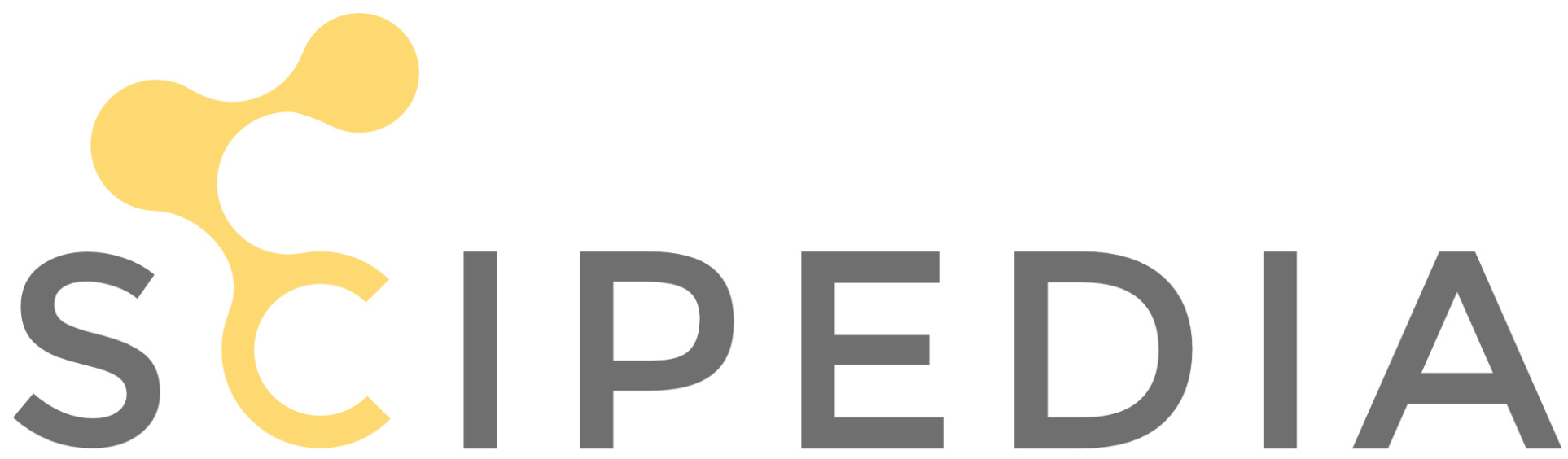

Register for free at https//www.scipedia.com to download the version without the watermark 